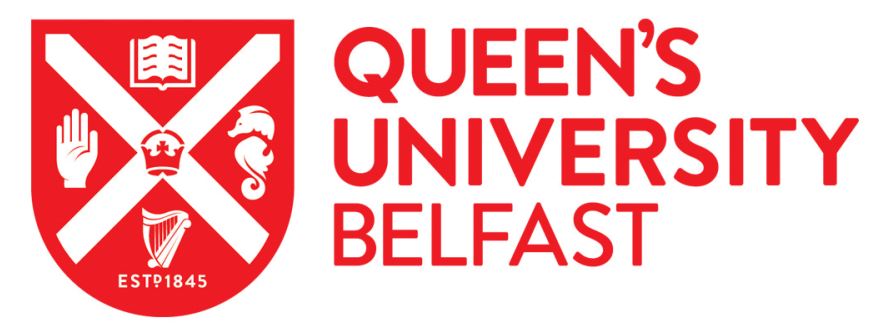

\title{
Developing a disease management program for the improvement of heart failure outcomes: the do's and the don'ts
}

Healy, L., Ledwidge, M., Gallagher, J., Watson, C., \& McDonald, K. (2019). Developing a disease management program for the improvement of heart failure outcomes: the do's and the don'ts. Expert Review of Cardiovascular Therapy, 17(4), 267-273. https://doi.org/10.1080/14779072.2019.1596798

\section{Published in:}

Expert Review of Cardiovascular Therapy

\section{Document Version:}

Peer reviewed version

Queen's University Belfast - Research Portal:

Link to publication record in Queen's University Belfast Research Portal

\section{Publisher rights}

(c) 2019 Informa, trading as Taylor \& Francis Ltd.

This work is made available online in accordance with the publisher's policies. Please refer to any applicable terms of use of the publisher.

\section{General rights}

Copyright for the publications made accessible via the Queen's University Belfast Research Portal is retained by the author(s) and / or other copyright owners and it is a condition of accessing these publications that users recognise and abide by the legal requirements associated with these rights.

\section{Take down policy}

The Research Portal is Queen's institutional repository that provides access to Queen's research output. Every effort has been made to ensure that content in the Research Portal does not infringe any person's rights, or applicable UK laws. If you discover content in the Research Portal that you believe breaches copyright or violates any law, please contact openaccess@qub.ac.uk. 


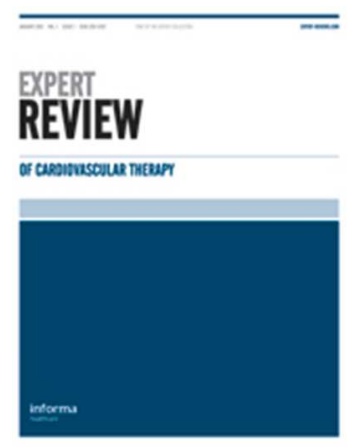

\section{Developing a disease management program for the improvement of heart failure outcomes: the do's and the don'ts}

\begin{tabular}{|r|l|}
\hline Journal: & Expert Review of Cardiovascular Therapy \\
\hline Manuscript ID & ERK-2018-0098 \\
\hline Manuscript Type: & Reviews \\
\hline Keywords: & $\begin{array}{l}\text { Chronic Heart Failure, Disease Management Program, Heart Failure/ } \\
\text { Therapy, Heart Failure/ Diagnosis, Patient-centred care }\end{array}$ \\
\hline \multicolumn{2}{|l}{} \\
\hline
\end{tabular}

SCHOLARONE $^{\text {m }}$

Manuscripts 
Section 1:

Heart Failure: The Societal Challenge

Heart failure presently affects $2 \%$ of adults in developed countries, and is a condition associated with a well-documented reduction in life expectancy and a morbidity burden and quality of life similar to many cancers. Of concern, is that the prevalence is expected to increase dramatically in the coming years ${ }_{[1]}$. This is partly due to an aging population with more than $10 \%$ of those aged 75 years suffering from this condition ${ }_{[2]}$. Prevalence is also increasing as a result of continued suboptimal management of risk factors for heart failure but also as a result of the positive developments in the treatment of patients with cardiovascular conditions associated with heart failure development ${ }_{[2]}$. The continued growth in the number of people suffering with heart failure challenges our present health care structures charged with delivery of care to this population. These structures historically, and to the present day, have focused on a reactive response to management of an immediate threat to the patient, and not the development of a coherent chronic disease management framework designed to link the hospital and community care management of patients' medical problems, which invariably are greater than one isolated chronic illness ${ }_{[3]}$. The lack of a coordinated proactive approach to care compromises outcomes, best exemplified by the hospital dependency of this population. Heart failure is the commonest cause for admission to hospital over the age of 65 years, and the resultant costs amounts to $70 \%$ of the heart failure budget now thought to consume approximately $2-3 \%$ of health care budgets in the western world ${ }_{[4,5,6,7]}$. The hospital burden of heart failure, if maintained at the present level, will in itself pose a serious threat to health care capacities given the projected increase in prevalence.

Section 2:

Heart Failure: The Medical Challenge Reflecting significant advances in the understanding of the pathophysiology and therapeutics of heart failure along with the ageing of the heart failure population there can be no doubt that this syndrome has become a complex medical challenge in modern day medicine. The evolution of our understanding of the pathophysiology has brought us to the definition of two distinct phenotypes of heart failure, reduced ejection fraction and preserved ejection fraction. While both examples of the heart failure syndrome, the approach to these two different phenotypes is significantly different. Recently the European society has defined a third phenotype of mid-range EF, reflecting an emerging debate as to whether those with minimally depressed systolic function reflect a potentially distinct subgroup $_{[8]}$. Along with this varied pathophysiology are the multiple conditions leading to 
HF all of which need to be addressed as potentially important in the overall management of the condition. In addition, the well-described comorbidity burden for patients with heart failure, with potential masking of symptoms and drug interactions adds to the complexity of management [9]. The above underline the need for specialist input in many phases of care of the HF syndrome. However, many reports underline that such input is lacking; hospital care for patients with acute decompensated heart failure is often provided by non-cardiology services, with less effective outcomes $_{[10,11,12,13,14]}$. In the community, many patients do not receive specialist advice in an environment where there is well-documented uncertainty and lack of confidence among general practitioners in the management of this condition ${ }_{[3,9]}$. Finally, while complex to the medical providers, HF for the above reasons has become a real challenge to the patient and his / her family members. Lack of understanding of what to do in day-to-day self-care leads to many problems often resulting in clinical deterioration and need for hospitalisation. Consequently, our structures of care need to focus on multidisciplinary input to ensure self-care education with focus on adherence to therapies, diet, exercise, along with management of anxieties and depression $[17,18]$

\section{Section 3 :}

Disease management Programmes (DMP's)

The complexity of the care of the heart failure syndrome, coupled with the growing epidemiological and health economic challenges of HF have resulted in a viewpoint that a new approach towards the disease was needed. This led to the development of heart failure disease management programmes (DMP's). These were first proposed in the 1990's and developed initially as a means of providing a more coordinated approach to care following hospital discharge aimed predominantly at reducing hospital readmission, accepted at that time as one of the most significant challenges in this cohort. The view was that these programmes should be specialist led with important input from nurses trained in heart failure care and other allied health care professionals. As initially conceived, and directed at post discharge care a lot of focus was put on titration of disease modifying therapies and consequently many programmes focused on the REF patient phenotype. There was little GP involvement and the service was often a time defined intervention to guide patients through the initial vulnerable period post discharge.

More recently a wider view of the role of DMPs has evolved ${ }_{[19]}$ to include stable patients, patients with HF-PEF and while this undoubtedly poses resource challenges it does allow attention to be given to the "well HF patient" to ensure optimal care is put in place at that stage reducing the chances of disease progression. A central aspect of DMP's should include identifying these patients 
at risk and preventing the natural decline of disease to the point of admission to hospital which is seen as a critical time point of the disease.

The result of these evolving views on what is the best structure for a DMP has led to multiple variants in practice from nurse-provided drug titration services to cardiologist-led multidisciplinary teams involved throughout the phases of the HF syndrome emphasizing the four central pillars of care; accurate diagnosis with complete work up of cause; precise application of proven therapies, patient and family education in self-care along with ready access for clinical deterioration (Fig. 1). The objective of these programmes is to provide a seamless transition to an outpatient care service with optimisation of therapeutic interventions in order to prevent progression of the disease.

Section 4:

Proof of Benefit

Disease management programmes have shown a reduction in the rates of re-hospitalisation, mortality outcomes and quality of life ${ }_{[17,18,19,20,21]}$. Simple approaches such as intensive follow up which is a key strength of DMP's can lead to improved outcomes. Nurse led patient education has demonstrated benefits. Nurse led home visits, family/caregiver education and telephone calls have resulted in a reduction in re-hospitalisation and mortality rates ${ }_{[18]}$. BNP-led screening and intervention along with oversight by heart failure physicians in an at-risk population has also been shown to reduce new onset failure and the prevalence of significant left ventricular dysfunction. [17]. Treatment of a community diagnosis of stable chronic heart failure in a DMP has also demonstrated positive benefits ${ }_{[21]}$. However not all studies have demonstrated good outcomes. A study in Denmark, demonstrated similar death rates and re-hospitalisation with patients managed in a heart failure clinic when compared to primary care ${ }_{[22,23]}$. An important point of this study however is that all patients were stabilised on heart failure treatments and educated on heart failure selfmanagement with the primary care cohort also receiving regular follow up too ${ }_{[23]}$.

\section{Section 5:}

Unanswered questions

There is no doubt as to the value of the disease management approach to heart failure care. However, while efforts need to be directed towards ensuring that this service is as widely available as is possible equal attention needs to be paid to addressing and answering as yet unanswered questions. These include the value of a DMP in the care of the more stable heart failure patients in 
the community where relatively little research has been carried out. Realising that cardiology directed care is likely best focused on the higher risk heart failure patient, work is required to determine optimal risk definition and the effectiveness of general practitioners taking the lead in care of the more stable cohort with access to specialist opinion where required. The recent demonstration of benefit of more evolved telehealth strategies ${ }_{[24]}$ underlines the need to further clarify to whom and when this more expensive form of surveillance should be applied.

\section{Section 6:}

Do's and Don'ts of setting up a heart failure clinic

In establishing a Disease Management Programme many issues need to be taken into consideration. Often, resource availability has the dominant influence on the development of the programme and decisions need to be taken as to what is most critical as the programme evolves. Nonetheless, the following are objectives worth considering while accepting that not all may be feasible. It should also be noted that some of the advice given herein reflects opinion based on experience and may not be supported by randomised clinical trials.

a) Programme management and multidisciplinary structure

Guideline and general consensus is that the multidisciplinary disease management programme needs to be led by a cardiologist with a specific interest in heart failure ${ }_{[8]}$. This patient cohort presents a complex challenge in cardiovascular management and therefore delegating major cardiovascular decisions to other members of the team will potentially compromise patient outcomes. A pattern has developed in some centres for heart failure clinics to be led for example by specialist nurses. In our view, this exposes the nurse to situations not covered by her/ his expertise and will lead to suboptimal care. However, many aspects of care of the heart failure patient can be effectively, safely and in certain circumstances more efficiently provided by other members of the team, under the guidance of the cardiologist lead. For example, these include patient and family education on disease monitoring, self-care by specialist nurses and titration of disease modifying therapy in those with a reduced ejection fraction phenotype by family practitioners, specialist nurses or pharmacists [25]. The prominent role of comorbidity among heart failure patients underlines the need for close links between programmes and specialists in other areas of medicine. In particular renal disease, diabetes, and care of the elderly. This ensures that the interaction of approaches to management of comorbidities are complimentary and optimal to those directed at heart failure care. The close links with the general practitioner is also critical in this regard, as this primary care physician coordinates the 
totality of care for the patient in many jurisdictions. Other important allied health care professionals are also important to the team effort, including the psychologist, nutritionist and physiotherapist. These important allied health care members of the team ensure effective advice and counselling is given to the patient and the family members regarding key critical areas. Of note, the psychological challenge of dealing with a chronic illness, importance of exercise training and nutritional advice. Contact with palliative care services should also be available to attend to the needs of patients entering the terminal phases of care for heart failure. Reflecting back on the issue of resources, it is likely that programmes many not be able to avail of all the above skill sets, but at a minimum the cardiologist, specialist nurse and general practitioner are essential members of the team.

\section{b) Clinic Structure}

Ideally, the programme structure should include an in-patient and out-patient component to the service. Patients admitted to hospital with acute decompensated heart failure (ADHF) are at immediate threat to survival, and also high risk of readmission in the weeks following discharge. Care of this cohort in hospital should be within a cardiology service as this has been shown to improve in-hospital outcomes $[26,27,28,22]$. Unfortunately, a significant proportion of patients admitted to hospital with a primary diagnosis of ADHF are admitted under general or noncardiac services, which can lead to incomplete investigation, suboptimal management and heighten the risk of immediate post discharge problems $[26,27,28,29]$ The in-patient phase of care also allows for the involvement of the allied health care members of the team to educate and coordinate self- care education, understanding of medication and other matters with both the family and the patient. This enhances safe discharge planning and allowing for a smoother course for the patient back in the community. Having a presence of the DMP within the hospital also allows for review of heart failure patients admitted to hospital for non-cardiovascular reasons. There is a concern that the management of such presentations in hospital can result in heart failure care being altered, sometimes without good reason, exposing the patient to post discharge complications. The full impact of this potential hazard has yet to be fully clarified but review of this cohort at discharge by a specialist heart failure nurse might represent an important intervention.

The outpatient component of the service needs to reflect the needs of the HF patient and should provide flexible cardiologist-led ambulatory outpatient care. Ideally this service should be available Monday to Friday to provide structured appointments for various needs and patient types. 
I. Post Hospital Discharge Follow Up.

This is the patient group on which the value of the disease management programme concept has been first established. Frequent review at clinics by the cardiologist, assisted by other members of the team, allied to telephonic contact and more sophisticated telehealth strategies has been shown in particular to reduce hospital readmissions [24].

II. Drug Titration Service.

This in particular is directed at those with a reduced ejection fraction phenotype and allows for efficient up-titration to maximum tolerated doses of the various disease modifying agents. This important aspect of care is effectively done by specialist nurse and / or pharmacists and unnecessary delay in titration can expose the patient to risk.

III. New Referrals from the Community.

Where possible the DMP structure should also provide access for patient referrals with potential new diagnoses of heart failure from the community. This at present would not be a standard component of many disease management programmes, reflecting resource constraint in the main, but it does facilitate earlier and accurate diagnosis with immediate implementation of best practice for this cohort.

IV. Process of Annual / interval review of stable Patients.

This patient group, which clearly includes all under the categories listed above, ensures a structured review at a designated time interval for all patients, excepting those for whom the treatment plan is palliative. This allows for aspects of care to be updated reflecting advances in management that continue to occur. Without such a review, implementation of best practice among patients in the stable phase of the syndrome may be at best delayed or even not applied. A further benefit of this review would be to reinforce self-care education and other allied health care matters. Furthermore, this aspect of the DMP service does not necessarily require direct patient contact with the service, but could be achieved by remote review using modern technology $[30]$.

V. Deteriorating Patient

This clinic setting should also provide access for same day review for patients with a potential clinical deterioration and consider, where possible, rolling this service into the weekend general cardiology on-call service to ensure continuity of care where needed. Not to provide this type of service provides a mixed message to the patients, as part of their self- 
care commitment is to monitor for early signs of deterioration and to contact a member of their heart failure team without delay in those circumstances. Without prompt response patients will begin to question the validity of advice to them to contact the services urgently. This "acute service "component of a HF unit, often involving outpatient intravenous therapies, is very effective at aborting the need for admission ${ }_{[31]}$ and in our experience is required by approximately $30 \%$ of patients in the first three months post discharge ${ }_{[32]}$.

VI. HF PEF Patient population

When first conceived, the DMP was developed predominantly to look after patients following hospital discharge admitted for management of heart failure, and to ensure proven disease modifying therapies were appropriately prescribed in those with reduced ejection fraction. This initially led to the exclusion of patients with preserved ejection fraction heart failure (HF-PEF) and still some programmes may not include this cohort on a routine basis. This approach was reasonable initially given the urgent needs of HF-REF patients in this setting and in certain circumstances constrained resources. However, given that the raison d'etre of the DMP is to provide optimal care to all patients with heart failure, and the fact that the morbidity burden of those patients with HF-PEF is as challenging as those with REF it is incumbent on those involved in these clinics to consider expanding enrolment to patients with heart failure irrespective of phenotype ${ }_{[33,34]}$. Benefit occurs to all phenotypes reflecting the importance of self-care, general cardiovascular care and close links with other specialities on comorbidity management in HF-PEF.

VII. HF Prevention Component To DMP

The increasing prevalence of heart failure, with the growing dominance of the PEF syndrome for which we still lack effective disease modifying therapies, underlines the need for the evolution and development of a clinically and cost-effective approach to the prevention of heart failure. An approach based on natriuretic peptide-based intervention has been recently demonstrated to be clinically effective reducing the development of new onset heart failure and the prevalence of significant ventricular dysfunction. Also shown to be cost-effective, consideration should be given within the structure of the DMP to propagating this concept to the primary care physicians and to linking in with them on its application. 
C. Dissemination of knowledge to other health care providers

With the growing prevalence of heart failure and the need for care to be effectively and safely centred in the community, it is important that confidence in management of the condition can be enhanced. Several publications have underlined the concerns of the family physicians in regard to certain aspects of HF care $[3,9,23,35]$. These include the diagnosis of heart failure, the concept of HFPEF, interpretation of diagnostics, and confidence in application of therapies. Therefore, while continuing to maintain close contact with the specialist services it is important for the DMP structure to take on an education role to improve decision making outside of the specialist environment. There are many ways that this can be achieved, including the standard education structures. In addition to standard approaches we have recently developed the virtual consultation model to provide on-line case management advice to the GP without the need for the patient to travel ${ }_{[30]}$. Given the group nature of this structure and the case discussion format we have demonstrated a significant improvement in competencies among family practitioners with regard to heart failure care. The intermediate and long-term benefit of this will be to enhance local decision making in a safe manner and thereby maintain the specialist resource of the DMP for more specialised aspects of HF care.

\section{Conclusion}

Supported by international guidelines, the development of disease management programmes for heart failure care is now an absolute requirement for effective care of this condition. While, as with all other interventions in medicine, unanswered questions remain, there is no doubt that the fundamental benefits of this approach are well established. The efforts of cardiovascular, general medicine and family practitioner representative bodies should now be focused on lobbying for sufficient resources to establish what is proven, and for funds to direct research at remaining and developing questions on the application of this intervention. Finally, learnings from this experience should be applied where applicable to management of other chronic illnesses leading to a more integrated approach to chronic disease 
6. Townsend N, Wickramasinghe K, Bhatnagar P, Smolina K, Nichols M, Leal J, Luengo, Fernandez R, Rayner M. Coronary Heart Disease Statistics (2012 edition). London: British Heart Foundation; 2012. Available from: http://www.bhf.org.uk/publications/viewpublication.aspx?ps=1002097.

7. Takeda A, Taylor SJ, Taylor RS, et al. Clinical service organisation for heart failure. Cochrane Database Syst Rev 2012; 9:CD002752.

8. McMurray JJ, Adamopoulos S, Anker SD, et al. ESC Guidelines for the diagnosis and treatment of acute and chronic heart failure 2012: the task force for the diagnosis and treatment of acute and chronic heart failure 2012 of the European Society of Cardiology. Developed in collaboration with the Heart Failure Association (HFA) of the ESC. Eur Heart J 2012; 33: 1787-847.

9. Luttik ML, Jaarsma T, van Geel PP, Brons M, Hillege HL, Hoes AW, de Jong R, Linssen G, Lok DJ, Berge $M$, van Veldhuisen DJ. Long-term follow-up in optimally treated and stable heart failure patients: primary care vs. heart failure clinic. Results of the COACH-2 study. Eur J Heart Fail. 2014 Nov;16(11):1241-8. doi: 10.1002/ejhf.173.

10. Boom NK, Lee DS, Tu JV. Comparison of processes of care and clinical outcomes for patients newly hospitalized for heart failure attended by different physician specialists. Am Heart J 2012; 163:252-259.

11. Foody JM, Rathore SS, Wang Y, Herrin J, Masoudi FA, Havranek EP, Krumholz HM. Physician specialty and mortality among elderly patients hospitalized with heart failure. Am J Med 2005; 118:1120-1125. 
12. Jong $\mathrm{P}$, Gong Y, Liu PP, Austin PC, LeeDS, Tu JV. Care and outcomes of patients newly hospitalized for heart failure in the community treated by cardiologists compared with other specialists. Circulation 2003;108: 184-191.

13. Bellotti P, Badano LP, Acquarone N, Griffo R, Lo Pinto G, Maggioni AP, Mattiauda C, Menardo G, Mombelloni P. Specialty-related differences in the epidemiology, clinical profile, management and outcome of patients hospitalized for heart failure: the OSCUR study. Eur Heart J 2001;22:596-604.

14. Patel JA, Fotis MA. Comparison of treatment of patients with congestive heart failure by cardiologists versus noncardiologists. Am J Health Syst Pharm 2005;62:168-172.

15. Adams KF, Jr., Fonarow GC, Emerman CL, LeJemtel TH, Costanzo MR, Abraham WT, Berkowitz RL, Galvao M, Horton DP, Committee ASA. Investigators. Characteristics and outcomes of patients hospitalized for heart failure in the United States: rationale, design, and preliminary observations from the first 100,000 cases in the Acute Decompensated Heart Failure National Registry (ADHERE). Am Heart J 2005; 149:209-216.

16. Johansson $P$, Nieuwenhuis $M$, Lesman-Leegte I, van Veldhuisen DJ, Jaarsma T. Depression and the delay between symptom onset and hospitalization in heart failure patients. Eur J Heart Fail 2011;13:214-219.

17. Ledwidge M, Gallagher J, Conlon C, et al. Natriuretic Peptide-Based Screening and Collaborative Care for Heart Failure The STOP-HF Randomized Trial. JAMA. 2013;310(1):6674. doi:10.1001/jama.2013.7588

18. Phillips CO, Wright SM, Kern DE, Singa RM, Shepperd S, Rubin HR. Comprehensive discharge planning with post discharge support for older patients with congestive heart failure: a meta-analysis. JAMA 2004;291: 1358-1367. 140.

19. Takeda A, Taylor SJ, Taylor RS, Khan F, Krum H, Underwood M. Clinical service organisation for heart failure. Cochrane Database Syst Rev 2012;9: CD002752, doi: 10.1002/14651858. CD002752.pub3

20. Yu DS, Thompson DR, Lee DT. Disease management programmes for older people with heart failure: crucial characteristics which improve post discharge outcomes. Eur Heart J 2006; 27:596-612.

21. James, S, Barton D, O'Connell E, Voon V, Murtagh, G, Watson C, Murphy T, Prendiville B, Brennan, D, Hensey M, O'Neill L, O'Hanlon R, Waterhouse D, Ledwidge M, Gallagher J, McDonald K. Life expectancy for community-based patients with heart failure from time of diagnosis. International Journal of Cardiology, vol 178, pp. 268-74. DOI: 10.1016/j.ijcard.2014.09.131. 
22. Clark AM, Savard LA, Thompson DR. What is the strength of evidence for heart failure disease-management programs? J Am Coll Cardiol. 2009 Jul 28;54(5):397-401. doi: 10.1016/j.jacc.2009.04.051.

23. Schou M, Gustafsson F, Videbaek L, Tuxen C, Keller N, Handberg J, SejrKnudsen A, Espersen G, Markenvard J, Egstrup K, Ulriksen H, Hildebrandt PR. Extended heart failure clinic followup in low-risk patients: a randomized clinical trial (NorthStar). Eur Heart J 2013;34:432-442.

24. Koehler F, Koehler K, Deckwart O, et al. Efficacy of Telemedical Interventional Management in Patients with Heart Failure (TIM-HF2): A Randomised, Controlled, Parallel-Group, Unmasked Trial. Lancet 2018; Aug 25.

25. Anderson SL, Marrs JC. A Review of the Role of the Pharmacist in Heart Failure Transition of Care. Advances in Therapy. 2018;35(3):311-323. doi:10.1007/s12325-018-0671-7.

26. Cleland J, Dargie H, Hardman S, McDonagh T, Mitchell P. National Heart Failure Audit: April 2011-March2012. London: National Institute for Cardiovascular Outcomes Research; 2012.

27. Boom NK, Lee DS, Tu JV. Comparison of processes of care and clinical outcomes for patients newly hospitalized for heart failure attended by different physician specialists. Am Heart J 2012;163:252-259.

28. Foody JM, Rathore SS, Wang Y, Herrin J, Masoudi FA, Havranek EP, Krumholz HM. Physician specialty and mortality among elderly patients hospitalized with heart failure. Am J Med 2005; 118:1120-1125.

29. Jong P, Gong Y, Liu PP, Austin PC, Lee DS, Tu JV. Care and outcomes of patients newly hospitalized for heart failure in the community treated by cardiologists compared with other specialists. Circulation 2003;108: 184-191.

30. Gallagher, J., James, S., Keane, C., Fitzgerald, A., Travers, B., Quigley, E., Hecht, C., Zhou, S., Watson, C., Ledwidge, M., and McDonald, K. (2017) Heart Failure Virtual Consultation: bridging the gap of heart failure care in the community - A mixed-methods evaluation. ESC Heart Failure, 4: 252-258. doi: 10.1002/ehf2.12163.

31. Ryder M, Murphy NF, McCaffrey D, O'Loughlin C, Ledwidge M, McDonald K. Outpatient intravenous diuretic therapy; potential for marked reduction in hospitalisations for acute decompensated heart failure. Eur J Heart Fail. 2008 Mar;10(3):267-72. doi: 10.1016/j.ejheart.2008.01.003.

32. Murphy TM, Waterhouse DF, James S, Casey C, Fitzgerald E, O'Connell E, Watson C, Gallagher J, Ledwidge M, McDonald K. A comparison of HFrEF vs HFpEF's clinical workload and cost in the first year following hospitalization and enrolment in a disease management program. Int J Cardiol. 2017 Apr 1;232:330-335. doi: 10.1016/j.ijcard.2016.12.057. 
33. Oktay AA, Rich JD, Shah SJ. The Emerging Epidemic of Heart Failure with Preserved Ejection Fraction. Current heart failure reports. 2013;10(4):10.1007/s11897-013-0155-7. doi:10.1007/s11897-013-0155-7.

34. Andersson C, Vasan RS. Epidemiology of heart failure with preserved ejection fraction. Heart failure clinics. 2014;10(3):377-388. doi:10.1016/j.hfc.2014.04.003.

35. Zoler ML. Primary Care endures in heart failure management. Cardiology News. 2016. Available from: https://www.mdedge.com/ecardiologynews/article/105796/heartfailure/primary-care-endures-heart-failure-management. 


\section{Disease Management}

Programme

Diagnosis with work up of cause

Easy access for clinical deterioration

Figure: 1 The four central pillars

of a disease management

Program (DMP) 